\title{
AUTOMATIZAÇÃO DA MODELAÇÃO BIM DE ARMADURAS NO PROJETO DE ESTRUTURAS
}

\author{
Margarida Borges $^{(1)}$, Patrício Rocha ${ }^{(2)(3)}$, José Lino $^{(2)}$, Ricardo Santos ${ }^{(4)}$ \\ (1) Instituto Superior de Engenharia do Porto, margaridamb.1992@gmail.com \\ (2) Newton - Consultores de Engenharia, Porto, jclino@newton.pt \\ (3) proMetheus, Instituto Politécnico de Viana do Castelo, Viana do Castelo, Portugal, \\ procha@estg.ipvc.pt \\ (4) CONSTRUCT-LESE, ISEP/ISEPBIM, rps@isep.ipp.pt
}

\begin{abstract}
Resumo
Com a introdução e o desenvolvimento de novas tecnologias a simplificação e substituição de processos ineficientes é cada vez maior, mesmo num setor tão antigo como o da AEC.

Atualmente a troca de informações entre um gabinete de engenharia e a obra ainda é um processo desnecessariamente complexo, principalmente no que respeita aos entregáveis de um projeto (e.g. localização e detalhe das armaduras em estruturas de betão armado; ligações em estruturas metálicas; etc.). Neste contexto, o desenvolvimento de um modelo estrutural com representação detalhada de todos os pormenores facilita a interpretação do projeto, a eventual deteção de zonas críticas e a otimização do planeamento do processo construtivo por parte de todos os profissionais envolvidos desde o engenheiro projetista ao construtor.

No presente artigo são propostas um conjunto de rotinas capazes de reproduzir automaticamente armaduras em lajes retangulares de betão armado, armadas em duas direções e apoiadas em todos os bordos, recorrendo à metodologia BIM. A introdução de dados e cálculos preliminares baseiam-se em folhas de cálculo MS-Excel, exportação e interpretação dos resultados recorrendo à programação visual em Dynamo e representação tridimensional automática no modelo BIM em Revit.
\end{abstract}

\section{Introdução}

Entre outras valências, o BIM facilita o desenvolvimento e utilização de modelos digitais, que simulam o planeamento, cálculo, construção e operação de uma dada construção. Assim, o resultado é um modelo de informação que caracteriza a geometria, relações espaciais, informações geográficas, quantidades e propriedades dos elementos de um edifício, além de estimativas orçamentais, mapas de quantidades e planeamento de trabalho. [1].

Considerando que é necessário produzir peças do projeto que representem detalhadamente os elementos de betão armado, o desenvolvimento automático de um modelo estrutural com a representação de todos os pormenores de armadura facilita a interpretação do projeto e a qualidade da informação que se pretende transmitir. Esta visão global potência a deteção de 
zonas de conflito e, consequentemente, a otimização do processo de planeamento e construção. Tendo em conta que na troca de informação de pormenorização pode haver múltiplos modos de comunicação entre o engenheiro da estruturas e o construtor, é da maior importância que essa mensagem seja passada o mais rigorosamente possível [2].

Apesar de todas as vantagens geradas pela nova metodologia, ainda continuam desaproveitadas várias das potencialidades que o BIM pode trazer, em particular, para a modelação de armaduras. Tendo em vista que esta área da engenharia civil é fortemente normalizada, conduzindo a soluções estruturais repetitivas, os projetistas podem apoiar-se nesta metodologia para o desenvolvimento de ferramentas informáticas que permitam a criação automática de certos objetos, em que a intervenção humana se cinja aos aspetos técnicos de relevo.

Procurando abranger os profissionais sem conhecimentos específicos em programação dita convencional, a Autodesk desenvolveu uma linguagem de programação visual, como extensão do Revit, o Dynamo, para ajudar os utilizadores a aproveitar todo o potencial do software 3D. Trata-se de uma plataforma de programação visual normalmente associado à modelação paramétrica e integrada de projetos. Esta plataforma que, dependendo das versões do software, poderá ser instalada como add-on ou, mais recentemente, surge pré-instalada com o Revit, permite compor e processar algoritmos personalizados que criam geometrias e manipulam modelos no Revit ou mesmo no próprio Dynamo. O processo de programação visual consiste em agrupar e organizar blocos de código (os 'Nós') que são programados para realizar uma determinada tarefa [3].

O presente artigo tenta preencher a lacuna da automação da pormenorização das armaduras em lajes retangulares de betão armado, armadas em duas direções, pormenorização essa que ainda não é suficientemente automatizada nos softwares comerciais, para poder dar resposta total às necessidades dos projetistas [4]. Usando um conjunto de programas informáticos comuns no setor (e.g. o Excel da Microsoft; e o Revit e o Dynamo da Autodesk) foram desenvolvidas rotinas interligadas que culminam na modelação das armaduras num ambiente 3D. O processo começou com o desenvolvimento de uma folha XLMS contendo a automatização de alguns métodos tradicionais de determinação dos momentos fletores atuantes, para efeitos de dimensionamento de lajes de betão armado (alternativamente, também é permitida a introdução dos valores finais dos referidos momentos fletores, obtidos através de outros processos ou de programas de cálculo automático) e a respetiva determinação das armaduras. Após a determinação das armaduras, uma rotina do Dynamo, que atende à saída de dados da folha Excel, serve como ligação intermediária entre o MS-Excel e o Revit, onde os elementos de armaduras serão gerados. Considerando que o algoritmo desenvolvido tem como alvo o dimensionamento de painéis de laje com continuidade, o programa pode ser executado consecutivamente de forma a armar todos os painéis de laje, um de cada vez, desde que todos tenham as mesmas dimensões e estejam sujeitos às mesmas cargas.

\section{Plataforma de cálculo de armaduras}

O conjunto de folhas em MS-Excel desenvolvidas para o dimensionamento das armaduras recorre a macros, bem como à programação geral de células e produz informação imprescindível à implementação do programa Dynamo associado, calculando as armaduras necessárias para qualquer laje bidirecional retangular apoiada em todos os bordos. 


\subsection{Introdução e recolha de dados da laje}

A folha que abre o programa Excel apresenta uma secção introdutória (ver Figura 4), que esclarece: as funcionalidades e limitações do programa; a convenção de momentos fletores utilizada; e a primeira etapa do Guia de Utilizador, designada por "Dados".

É importante realçar que as arestas Lx e Ly não correspondem ao maior e menor vão da laje retangular, mas sim à aresta paralela ao eixo $\mathrm{X}$ e ao eixo $\mathrm{Y}$, respetivamente (ver Figura 4).

Também é importante o reconhecimento do esquema de cores adotada na folha Excel e no programa Dynamo, que foi criada para facilitar a interação do utilizador com o programa. $\mathrm{O}$ utilizador pode apenas editar e/ou clicar em campos azuis, estando impedido de alterar as células em tons de cinza. Os elementos rosa e verde estão ligados aos dados e informações que dizem respeito ao dimensionamento paralelo ao bordo Lx e Ly da laje, respetivamente.

As colunas que correspondem à etapa "Dados" dizem respeito à recolha de dados da laje em estudo, nomeadamente em relação aos seus materiais, geometria, ações, condições de apoio e métodos de cálculo.

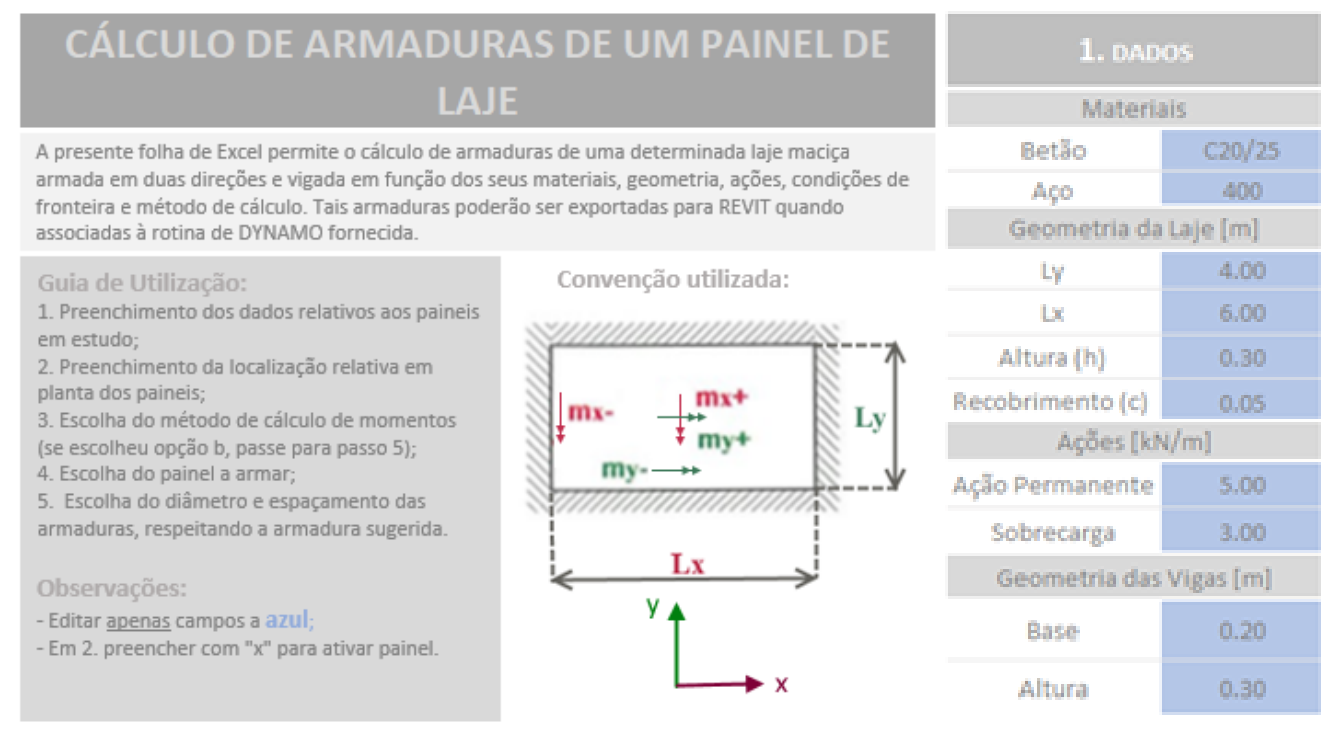

Figura 4: Extrato da folha de abertura.

\subsection{Análise Estrutural}

As etapas 2 e 3 do Guia de Utilizador são denominadas "Representação em planta" e "Obtenção de Momentos", respetivamente, (ver Figura 5). Esta última distingue o caminho que o utilizador escolhe no que diz respeito à análise estrutural, por sua separação em opções a) Cálculo automático de momentos máximos e b) Introdução manual de momentos máximos.

A opção a) utiliza três métodos para o cálculo dos momentos fletores atuantes: o primeiro que se apoia nas tabelas publicadas por Pedro Jiménez Montoya et al. na sua obra "Hormigón Armado" [5]; o segundo que resulta da adaptação do primeiro e propõe uma metodologia para incluir a alternância de sobrecarga e a redistribuição dos momentos fletores; e o terceiro que se apoia nas tabelas da norma britânica BS 8110-1: 1997 - "Structural use of concrete" [6]. 


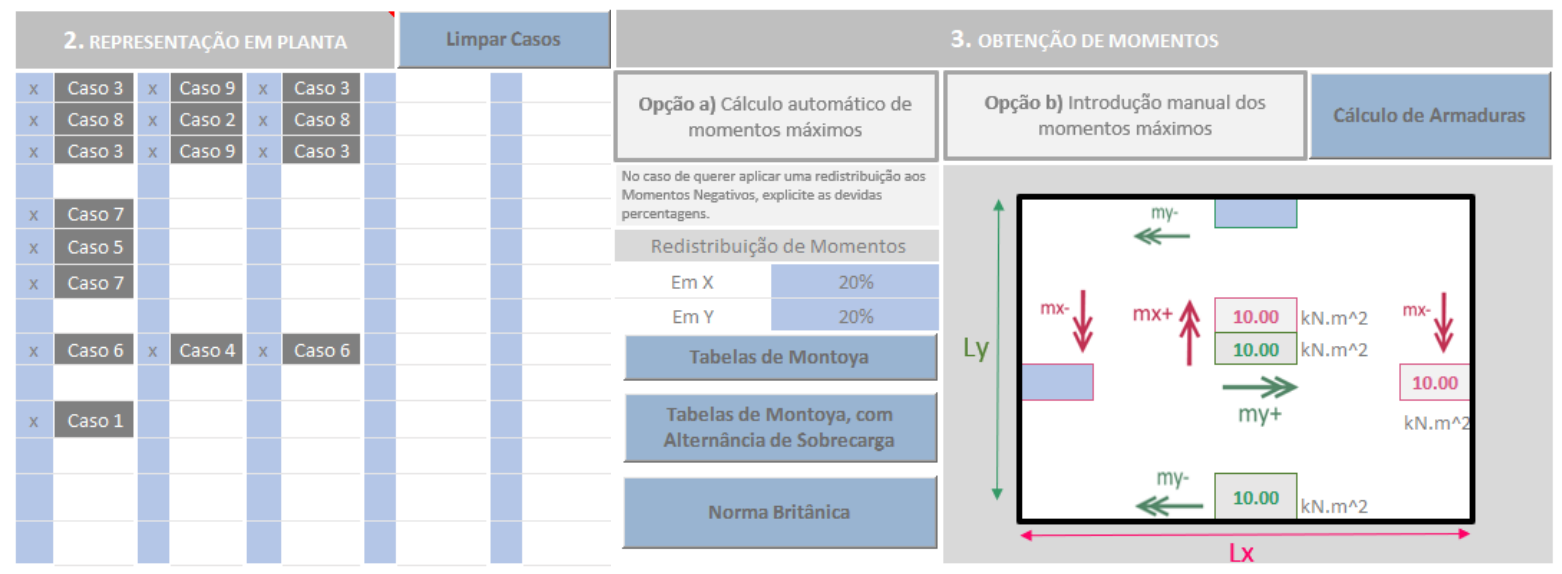

Figura 5: Etapas 2 e 3 do Guia de Utilizador.

Esta opção contém três botões programados com macros para cada um dos métodos de cálculo especificados, bem como um campo para especificar a percentagem de redistribuição dos momentos negativos. $\mathrm{O}$ recurso a esta opção requer a utilização da etapa "Representação em planta", que representa a quantidade e a localização relativa dos painéis de laje em estudo, por meio da ativação de células do Excel, simbólica dos próprios painéis de laje. Essa ativação, obtida com a inserção da letra " $x$ " nas células azuis, cria células cinzas no seu lado direito, com o caso das condições de apoio. Existem no total nove casos de condições fronteira que diferenciam todas as condições de continuidade previstas para lajes bidirecionais retangulares apoiadas em todos os bordos.

No entanto, se for necessário fazer uso de um software de análise estrutural externo, como (e.g. o Robot Structural Analysis) a opção b) deve ser considerada. Esta opção contém uma representação simbólica de uma laje com seis células editáveis relativas aos momentos fletor positivo e negativo. Embora o preenchimento destas células seja bastante direto, os momentos negativos devem ter em consideração quais das quatro arestas da laje têm uma continuidade.

Depois de definidos os momentos fletores para uma dada laje, o utilizador deve utilizar o botão "Cálculo de Armaduras", acima da representação do painel da laje, que redirecionará a folha de Excel para a quinta etapa do Guia do Utilizador.

\subsection{Seleção do Painel de Laje}

Caso a opção a) tenha sido escolhida, a seleção de um dos três botões correspondentes aos métodos de cálculo conduz o programa para uma nova folha de Excel, para o quarto passo "Escolha do Painel", representado na Figura 6, que permite a seleção de um dos painéis para estudo, gerado em "Representação em planta". Estes painéis são representados por um conjunto de células denominadas pela sua condição de apoio. Esta disposição é organizada por um sistema de grelha, representado por letras no eixo x e números no eixo $\mathrm{y}$, de forma a identificar o painel da laje que o utilizador deseja estudar. Ao clicar no botão "Cálculo de Armaduras", o programa redirecionará o utilizador para a terceira folha de Excel e última etapa do programa. 


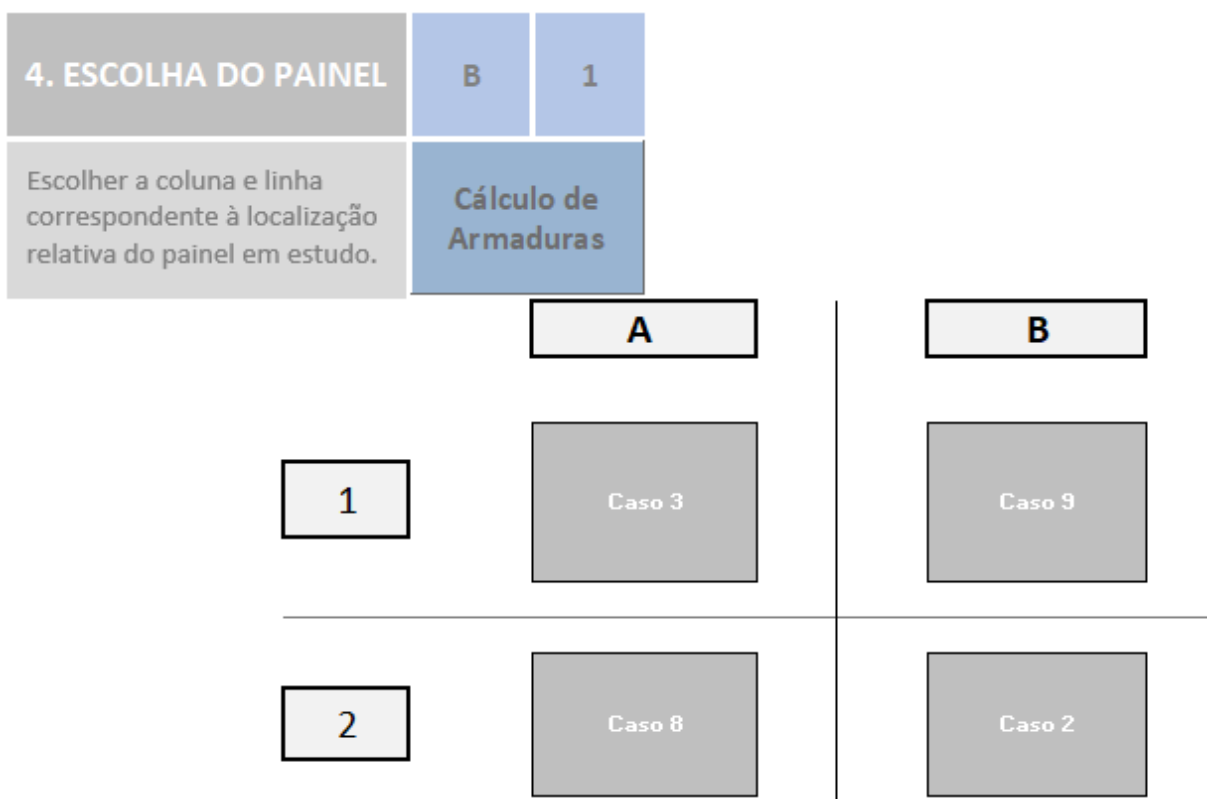

Figura 6: Etapa 4 do Guia do Utilizador.

\subsection{Interface de Armaduras}

A quinta e última etapa do Guia de Utilizador, "Seleção de Armaduras", fornece opções de escolha para zonas de armaduras orientadas por valores de cálculo para todas as zonas de reforço numa laje retangular armada em duas direções.

O processo de dimensionamento de armaduras, independentemente da zona de reforço, passa por uma conversão inicial dos valores de momentos fletores em áreas de armadura e, finalmente, em soluções de distribuição das armaduras. Neste processo estão contempladas todas as verificações ao Estado Limite Ultimo de flexão sugeridas pelo Eurocódigo 2 [7].

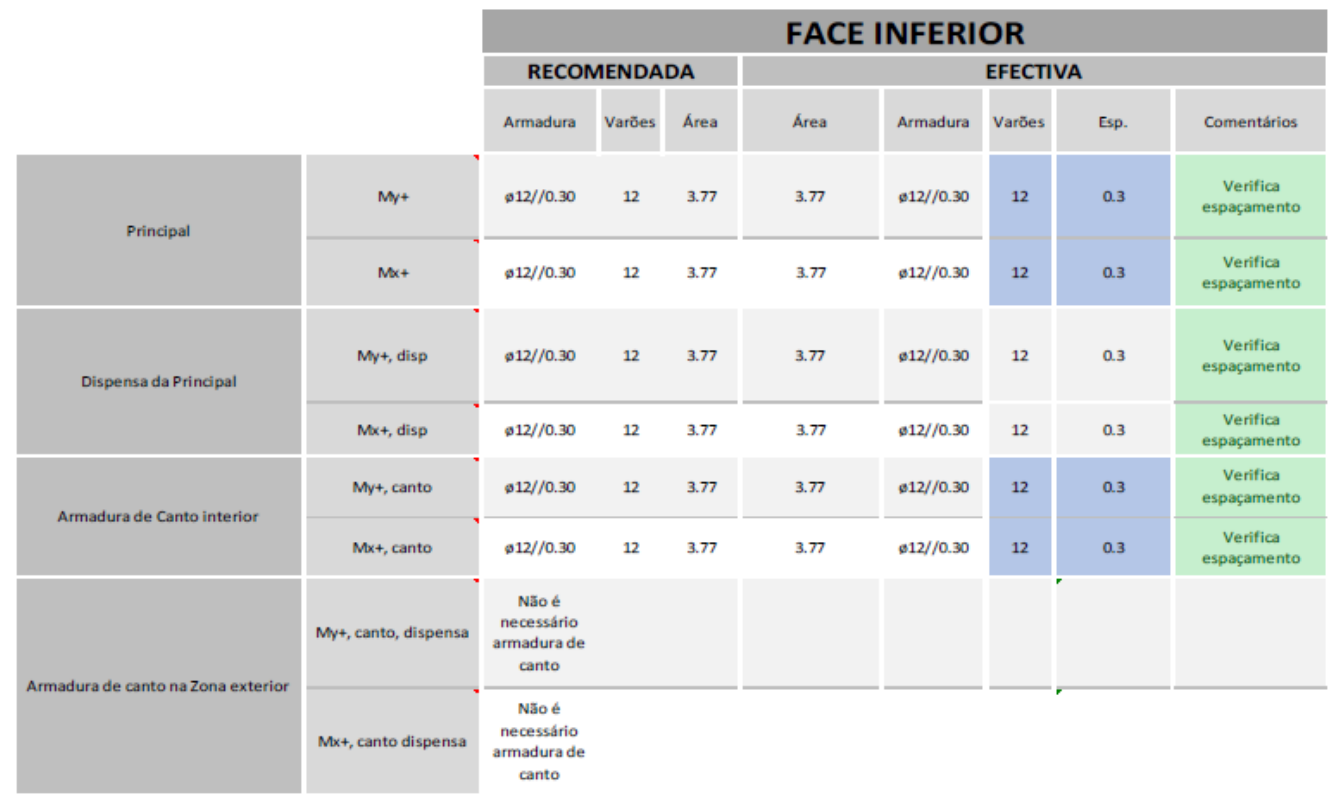

Figura 7: Seleção de armaduras da face inferior da laje. 


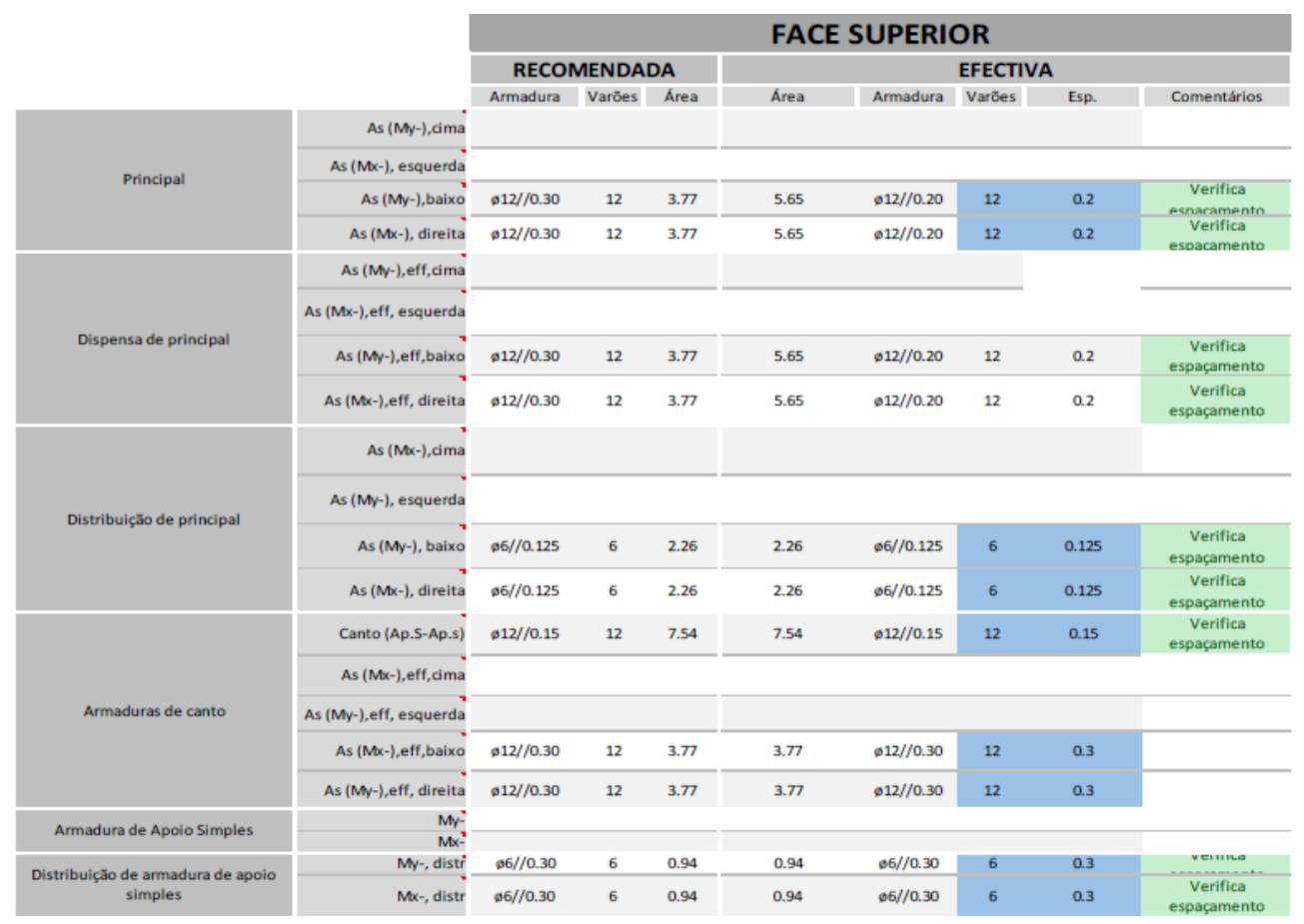

Figura 8: Seleção de armaduras da face superior da laje.

Para a face inferior e superior da laje, o programa especifica uma solução de distribuição das armaduras, vistas na Figura 7 e Figura 8, respetivamente. No entanto, a solução de armaduras sugerida pode ser alterada pelo utilizador: pode alterar o diâmetro e o espaçamento para os desejados que o programa verifica se satisfazem a área de armadura e o espaçamento mínimo e máximo. Depois de aceites todas as armaduras efetivas, as atividades na Folha de Excel cessam na perspetiva do utilizador e o programa fica preparado para calcular todos os dados necessários para fornecer à rotina do Dynamo. A síntese dos dados é compilada numa folha chamada "Saída" e as suas informações referem-se principalmente a medições e quantidades necessárias para definir varões de armaduras.

\section{Rotina Dynamo}

Esta secção reúne os procedimentos realizados no software de programação visual Dynamo e transforma os dados retirado do Excel em elementos de armaduras 3D no Revit. A rotina Dynamo coloca os elementos mencionados no modelo geométrico da laje preexistente e executa a rotina as vezes necessárias, em conformidade com a Folha de Excel, até percorrer todos os painéis dimensionados. Assim, é vital uma correspondência geométrica entre o painel de estudo no Revit e os dados inseridos no Excel, pois a rotina Dynamo não está programada para verificar ou comparar quaisquer parâmetros entre os dois programas e será executada independentemente das inconsistências geométricas.

Durante o desenvolvimento da rotina do Dynamo, notou-se que os 'Nós' definidos na ferramenta não tinham todas as funcionalidades para criar a rotina em causa e assim foi necessário recorrer a pacotes de 'Nós' de terceiros. Para o correto uso da rotina, para além da instalação dos programas de base Dynamo e Revit 2018, o utilizador deve instalar os seguintes pacotes: "Beaker", "BIM4Struct", "Bumblebee" "Dynamo for Rebar" e "LunchBox", disponibilizados online. 
Com o objetivo de obter uma leitura mais simples do programa, a rotina foi dividida em quatro secções principais com base na sua função, conforme apresentado na Figura 9. A primeira secção, com grupos de cores azuis, é a única em que o utilizador pode intervir. O segundo grupo com grupos cinza é um conjunto de informações gerais para fornecer às duas últimas secções. A terceira secção processa informação relacionada às armaduras da face inferior da laje, enquanto a última faz o mesmo relativamente à face superior. Ambas as secções são divididas, por grupos de 'Nós' verde e rosa, referentes à criação da armadura para My e Mx, respetivamente.
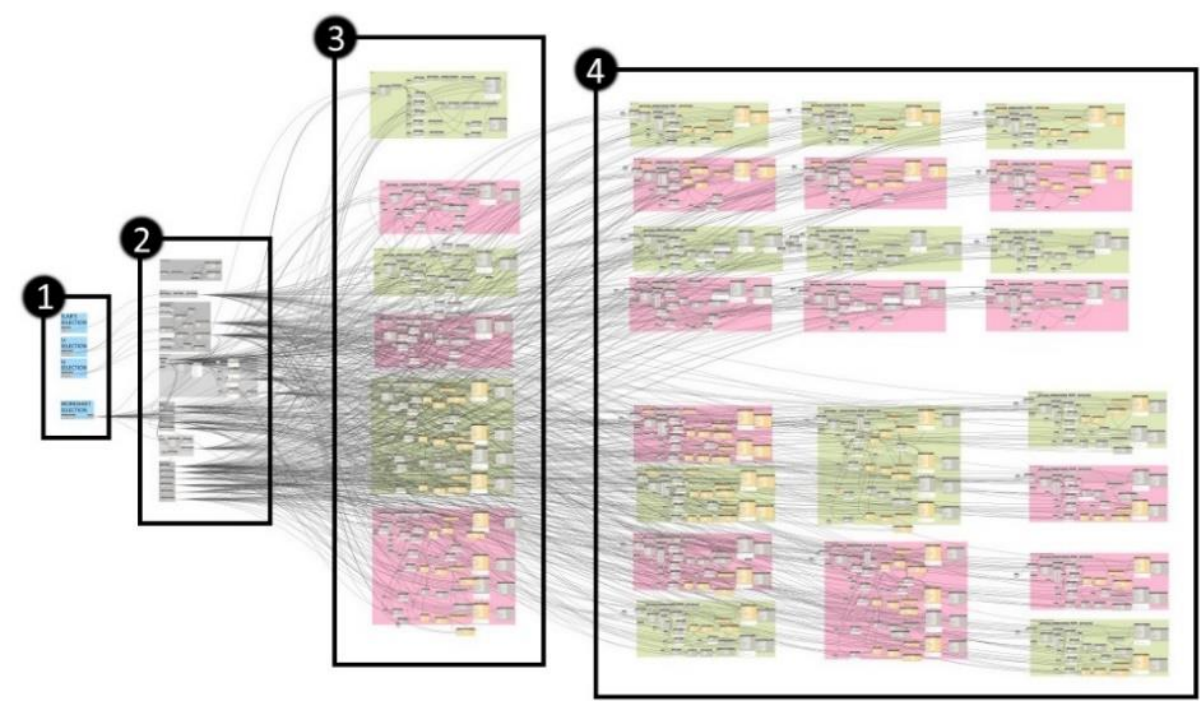

Figura 9: Disposição da rotina Dynamo.

\subsection{Secção de entrada de dados}

A primeira secção é definida por quatro grupos de 'Nós', correspondendo cada 'Nó' a um tipo de seleção manual no modelo Revit. Um dos grupos contém um 'Nó' responsável pela seleção do caminho no computador do utilizador para o ficheiro de Excel, de forma a ler as suas informações. Outro 'Nó' devolve o ID do elemento Revit da laje em estudo, servindo como ligação entre as armaduras a gerar e o seu painel de lajes hospedeira. Os dois grupos de 'Nós' restantes estão relacionados com seleção dos bordos Lx e Ly da laje mais especificamente às arestas Lx inferior e Ly esquerda da face superior da laje, como mostra a Figura 10.

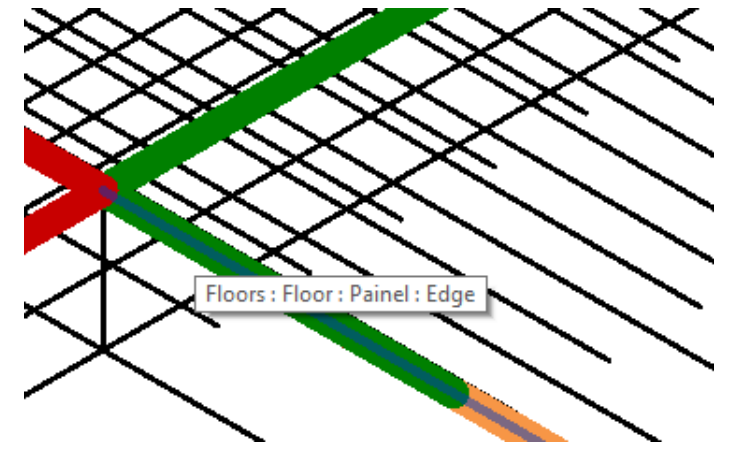

a) Seleção de Lx

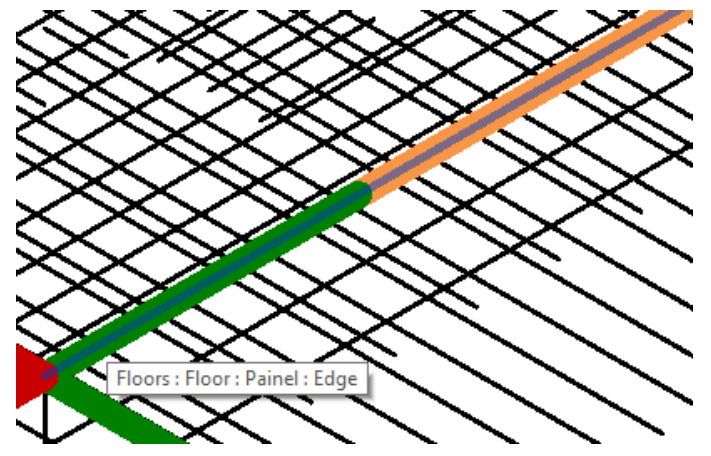

b) Seleção de Ly

Figura 10: Seleção de arestas. 


\subsection{Processamento de Dados Gerais}

A segunda secção da rotina do Dynamo prepara e resume as informações que servirão de dados de entrada necessários em vários 'Nós' para a criação de armaduras. Considerando que a saída de um único 'Nó' pode ser usada como entrada de vários 'Nós', esta secção foi isolada para aproveitar ao máximo o desempenho do Dynamo no processo de dados sistemáticos e repetitivos.

\subsection{Rotina de criação de armaduras}

As terceira e quarta secções são constituídas por 28 grupos de 'Nós' no total, seis dos quais criam as armaduras da face inferior e os restantes são responsáveis pela geração das armaduras da face superior. Embora resultem em diferentes varões de armaduras, todos estes grupos têm processos de criação semelhantes pois todos convergem nos mesmos dois 'Nós' finais, denominados "Rebar.ByCurve" e "Rebar.SetLayoutAsNumberWithSpacing", (ver Figura 11). O primeiro 'Nó' é responsável pela definição de um único varão de armadura e o segundo nó tem a função de o replicar o número de vezes necessárias, de acordo com o espaçamento definido.

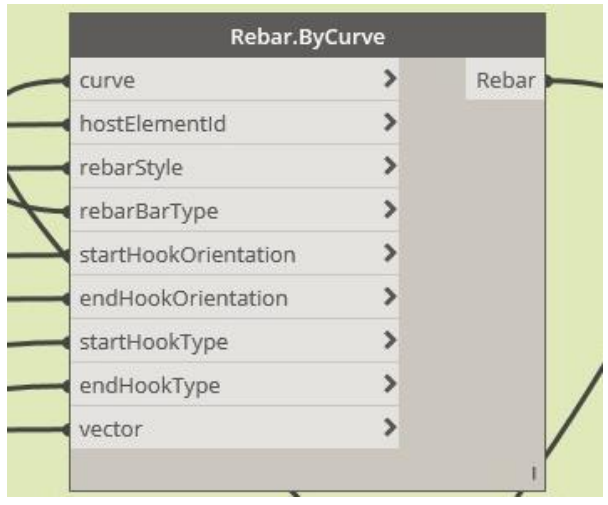

a) "Rebar.ByCurve"

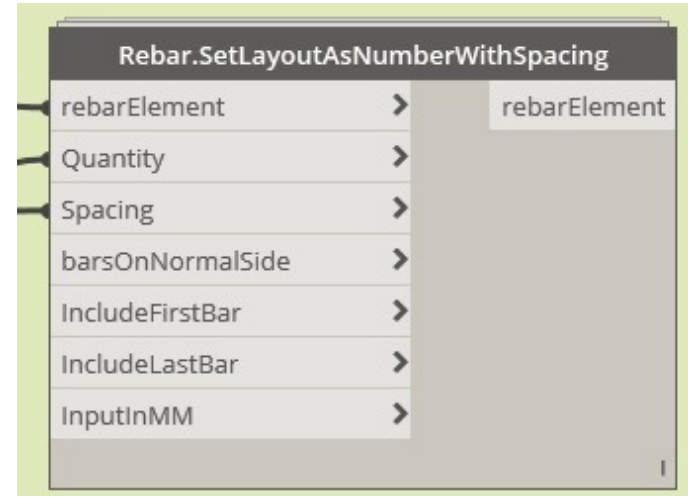

b) "Rebar.SetLayoutAsNumberWithSpacing"

Figura 11: 'Nós' de criação de varões.

Na sua maioria, os dados de entrada destes 'Nós' são lidos na folha de Excel, enquanto as informações restantes vêm da segunda secção da rotina. Cada um dos grupos é responsável pela criação de um conjunto de varões de uma única direção (daí as cores do grupo, como mencionado anteriormente). Embora o processo seja idêntico de grupo para grupo, o que os torna únicos é a análise de diferentes linhas de Excel que podem incluir até 12 valores/células por linha. Os valores dessas células reúnem todas as informações necessárias para distinguir zonas de armaduras específicas. Esse conjunto de linhas compõe uma tabela na Folha "Saída", mencionada na secção anterior. Um pequeno extrato desta tabela é mostrado na Figura 9.

\begin{tabular}{|c|c|c|c|c|c|c|c|c|c|c|}
\hline & $\varnothing$ & // & $x$ & $y$ & Distribution & $\begin{array}{c}\text { № of } \\
\text { Rebars }\end{array}$ & Rebar Length & Hook start & Hook End & $/ / \mathrm{mm}$ \\
\hline Asy+ & 8 & 0.15 & 0.95 & -0.075 & 5.1 & 35 & 5.15 & Standard - 90 deg. & Standard - 90 deg. & 150 \\
\hline Asxt & 8 & 0.2 & 0.825 & 0.825 & 3.35 & 17 & 6.25 & None & 'Standard - 90 deg. & 200 \\
\hline Asy+,int & 8 & 0.15 & 0.125 & -0.075 & 6.75 & 46 & 5.15 & Standard - 90 deg. & Standard - 90 deg. & 150 \\
\hline As $x+$,int & 8 & 0.2 & -0.325 & 0.125 & 4.75 & 24 & 7.45 & None & Standard - 90 deg. & 200 \\
\hline
\end{tabular}

Figura 12: Tabela da folha 'Saída'. 


\subsection{Criação de um varão de armadura}

De um modo geral, o processo do Dynamo usado para criar um único varão, passa por definir um segmento de reta e aplicar-lhe características de armadura. Por sua vez, para definir um segmento de reta, a abordagem passou por aplicar uma certa distância a um ponto através de um vetor e movê-lo para o seu local na laje de acordo com o sistema de coordenadas do painel. A sequência de 'Nós' usada no software de programação visual para criar um primeiro varão, mostrado na Figura 13, incluem um 'Nó' de criação de pontos e linhas, seguido por um conversor do sistema de coordenadas e, por último, um nó que transforma o segmento de reta numa curva, necessária para executar o nó "Rebar.byCurve".

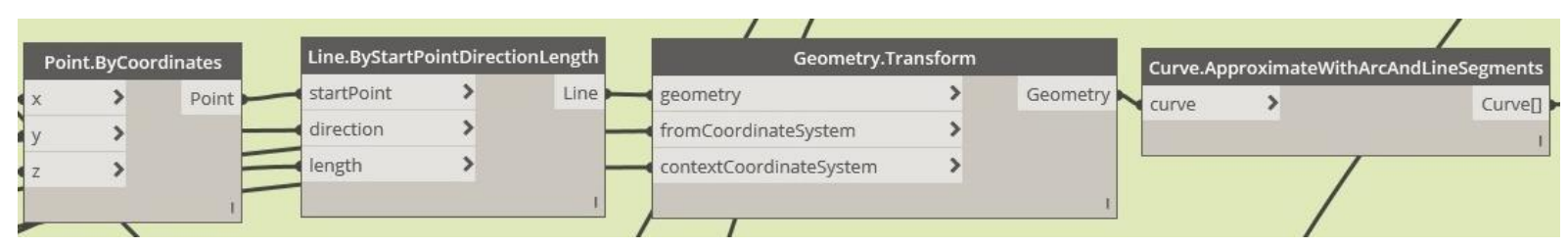

Figura 13: 'Nós' de criação de segmentos de retas.

O quarto parâmetro de "Rebar.ByCurve", denominado "RebarBarType", define o tipo de varão a ser aplicado ao segmento de reta criada: diâmetro e tipo de aço. Ambos os dados são previamente selecionados pelo utilizador no Excel e, no final da rotina Dynamo, são usados para definir uma expressão que define os tipos de armadura no Revit. Por exemplo, um varão de armadura S400 com um diâmetro de 12 mm é denominado, no Revit, como "12 400S". Assim, reunindo os dois termos por meio de 'Nós', pode-se evitar uma entrada manual repetida do tipo de armadura a ser aplicada. O conjunto de 'Nós' que permite a representação é apresentado na Figura 14.

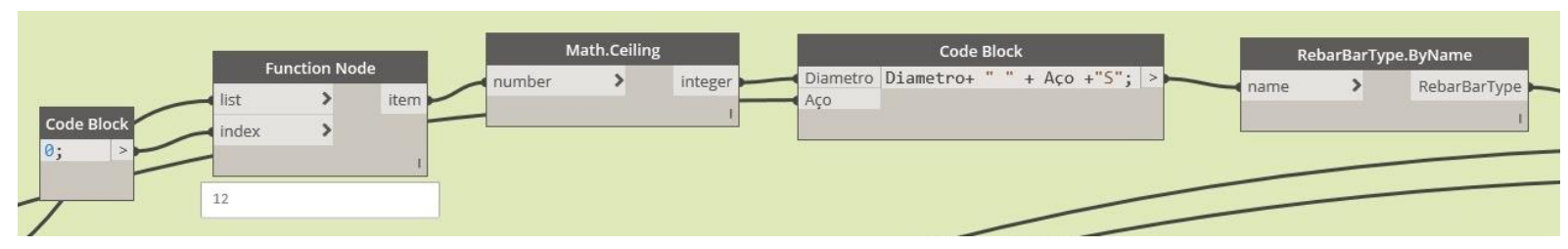

Figura 14: 'Nós' de criação de armaduras.

Os parâmetros do quinto ao oitavo 'Nó' do tipo "Rebar.ByCurve" permitem a definição da amarração de armaduras, sendo que os dois primeiros estabelecem a orientação inicial e final do varão e os dois restantes o seu tipo. Enquanto a maioria dos tipos de amarração inicial e final das zonas de armadura é constante, independentemente do painel, nas armaduras principal da superfície inferior uma potencial continuidade influencia o tipo de amarração. Nessas circunstâncias, a amarração da armadura principal positiva varia de painel para painel e as condições de início e fim do varão necessitam ser programadas no Excel. Neste programa, os tipos de amarração utilizados foram denominados "Nenhum", em zonas de continuidade, e "Padrão - 90 graus", fazendo o varão dobrar 90 graus. Todo as armaduras correspondentes à face inferior dobram para cima na viga e, no caso da superfície superior, dobram para baixo, (ver Figura 12). 


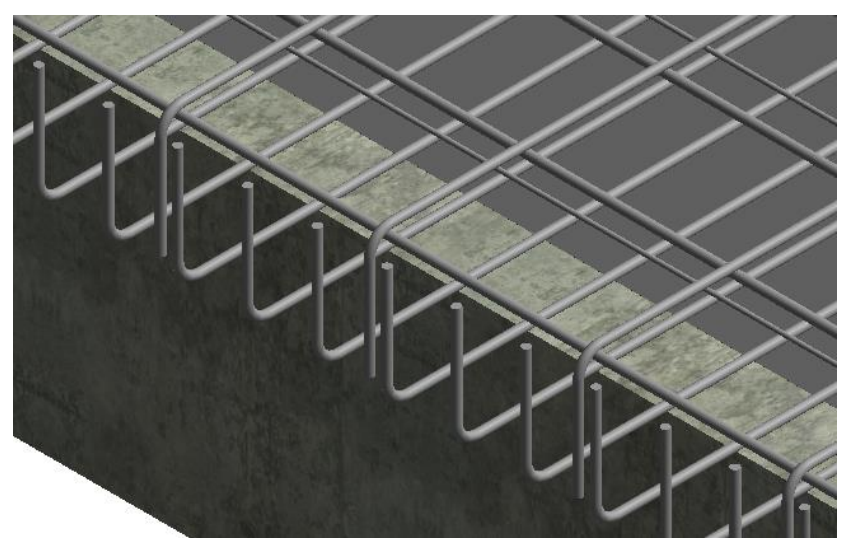

Figura 15: Amarração no Revit.

O último parâmetro necessário para criar o primeiro varão é chamado "Vetor" e ditará a direção em que o varão será replicado. Dentro desta rotina de Dynamo, esse vetor pode apenas ser definido em duas direções perpendiculares, pois numa laje retangular, todas as armaduras paralelas ao lado Lx do painel serão replicadas ao longo do lado Ly e vice-versa.

\subsection{Replicação de varões}

O 'Nó' do tipo "Rebar.SetLayoutAsNumberWithSpacing" possui apenas três parâmetros que potencialmente diversificam no seu valor de entrada, enquanto os quatro últimos têm uma opção padrão programada que se ajusta à rotina atual em todos os tipos de armadura. Como referido anteriormente, este nó replica o varão inicial um certo número de vezes com um espaçamento fixo; portanto, os três parâmetros mencionados correspondem a "RebarElement", "Quantity" e "Spacing". A primeira entrada corresponde à saída de "Rebar.ByCurve" e as próximas duas são lidas no Excel. A quantidade é calculada dividindo o comprimento da distribuição de armadura pelo espaçamento definido pelo utilizador e adicionando uma unidade ao resultado, para contabilizar o primeiro varão. Como pode ser observado na Figura 12, o espaçamento entre as barras é definido na segunda e na última posição da tabela do Excel, em metros e milímetros, uma vez que a unidade do medidor é usada em toda a folha de Excel enquanto sua milésima unidade é necessária para "Rebar.SetLayoutAsNumberWithSpacing".

Este nó marca o final da geração 3D de cada zona de armaduras, criando uma família de varões Revit constituída pelos varões de cada zona. Estas famílias podem ser editadas no Revit, se houver necessidade, adicionando ou removendo varões, editando o seu comprimento, posição, tipo ou comprimento de amarração.

Um modelo com três painéis de lajes modelado em Revit e armado através da combinação descrita entre Excel, Dynamo e Revit consegue ser observada na Figura 16.

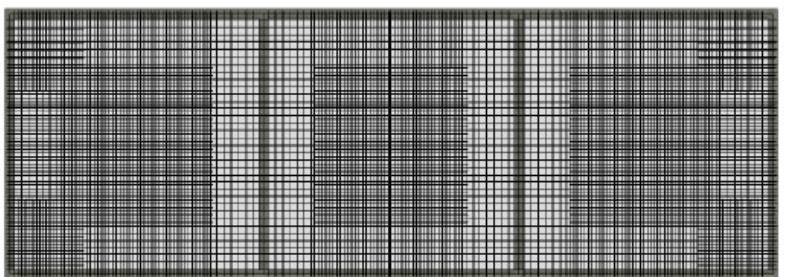

a) Armaduras da face inferior

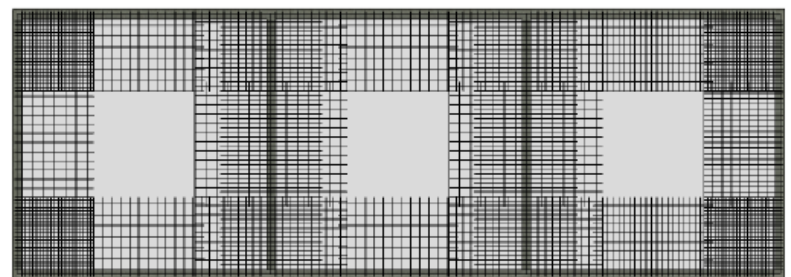

b) Armaduras da face superior

Figura 16 - Aspeto final das armaduras de uma laje com três painéis modelada em Revit 


\section{Conclusão}

O desenvolvimento do presente trabalho mostra as vantagens da introdução da programação visual na indústria da construção. $O$ vínculo entre o conhecimento de engenharia estrutural e as potencialidades da programação, que muitas vezes não se sobrepõem, abre um campo de possibilidades para o aparecimento de ferramentas poderosas que podem preencher qualquer lacuna ou ineficiência.

A dependência quase completa do Dynamo em relação à folha de Excel também facilitou o trabalho associado à programação visual, deslocando-o para a programação básica em Excel, que quase todos os engenheiros dominam. Dada a quantidade de casos, de condições de apoio para as lajes e zonas de armadura em consideração, a formatação das células do Excel e a programação de macros oferecem uma variedade de paradigmas condicionais que o Dynamo ainda não está pronto para hospedar com eficiência.

Embora as rotinas desenvolvidas sejam limitadas a lajes retangulares bidirecionais, esse tipo de trabalho pode ser um catalisador para casos de lajes mais complexos ou até mesmo a adaptação de alguns de seus conteúdos a outros elementos estruturais.

A disseminação da incorporação da programação visual na Engenharia Estrutural deve ser uma norma, não a exceção. A única barreira que impede que ela seja utilizada com mais frequência é o tempo gasto no desenvolvimento das rotinas e a quantidade adicional de tempo necessária para o Dynamo processar e reproduzir elementos de armaduras. Apesar disso, o esforço de detalhar manualmente qualquer projeto estrutural não se compara com as vantagens da metodologia BIM para adaptar, gerir e ajustar as necessidades do Engenheiro Estrutural em atender a todos os projetos.

\section{Bibliografia}

[1] S. Azhar, M. Hein, and B. Sketo, "Building Information Modeling (BIM): Benefits, Risks and Challenges," BIM-benefit Meas., vol. 18, no. 9, p. 11, 2007.

[2] I. F. do V. Gonçalves, "Aplicação do bim ao projeto de estruturas," Tese Mestr., 2014.

[3] T. Mousiadis and S. Mengana, "Parametric BIM: Energy Performance Analysis Using Dynamo for Revit," pp. 1-55, 2016.

[4] Henrique Pires, José Lino, Carlos Rodrigues, "Automatização da modelação BIM de armaduras no projeto de estruturas", Instituto Superior de Engenharia do Porto, 2018

[5] P. J. Montoya, Á. G. Meseguer, and F. M. Cabré, HormigonArmado, 14². Barcelona: Editorial Gustavo Gili, SA, 2000.

[6] BS 8110 - British Standard for the design and construction of reinforced and prestressed concrete structures. London: British Standard Institution, 1985.

[7] NP EN 1992-1-1 2010, Eurocódigo 2 - Projeto de estruturas de betão: Parte 1-1: Regras gerais e regras para edifícios. Portugal: IPQ, 2010. 